\title{
$\checkmark$ Cardiovascular risk and attitudes to lifestyle: what do patients think?//
}

\author{
Chris_Silagy, John_Muir, Angela|Coulter, Margaret [Thorogood, Liane_Roe
}

\begin{abstract}
Objective-To examine the relation between subjects' level of cardiovascular risk and their beliefs about the harmfulness of their smoking habit, current diet, and level of exercise, together with their stated desire to modify such behaviour.
\end{abstract}

Design-Self administered postal health and lifestyle questionnaire followed by a structured health check conducted by a nurse.

Setting-Five general practices in Luton and Dunstable, Bedfordshire.

Subjects-5803 people aged 35-64 years enrolled in the OXCHECK trial who attended for a health check before 1 March 1992.

Main outcome measures-Perceived risk to health of lifestyle behaviours, desire to modify behaviour, and a reported serious attempt to modify behaviour in the preceding year.

Results-A high proportion of smokers and those who were physically inactive perceived their behaviour to be harmful $(1020 ;(76 \% ; 95 \%$ confidence interval $74 \%$ to $79 \%$ ) and $350(74 \% ; 70 \%$ to $78 \%$ ) respectively) and wished to modify it (1212 (79\%; $77 \%$ to $81 \%$ ) and $375(74 \% ; 71 \%$ to $78 \%$ ) respectively). In contrast, only $289(45 \% ; 41 \%$ to $48 \%)$ of obese people and $188(14 \% ; 12 \%$ to $16 \%)$ of people with a high dietary fat intake perceived their current diet to be harmful. The more cardiovascular risk factors present, the more likely subjects were to perceive a health risk attached to their diet and lack of exercise $(p<0.01$ in both cases) and to want to improve their diet.

Conclusion-Awareness of the health risk from smoking and motivation to stop is high. Further efforts are required, however, to educate the public about the risks associated with a high dietary fat intake. Although the health risks of inactivity were University Department of Públic Health and Primary Care,Radcliffe Infirmary, Oxford) OX2 6HE

Chris Silagy, senior visiting fellow

John Muir, research fellow

Liane Roe, research

nutritionist

Health Services Research Unit, Department of Public Health and Primary Care,

Radcliffe Infirmary, Oxford OX2 6HE

Angela Coulter, deputy

director

Health Promotion Sciences Unit, Department of Public Health and Policy, London School of Hygiene and

Tropical Medicine,

London WC1E 7HT

Margaret Thorogood, senior research fellow

Correspondence to: Dr Silagy.

$B M F$ 1993;306:1657-60 widely recognised, motivation to take more exercise needs to be increased.

\section{Introduction}

The relation between lifestyle and cardiovascular disease is now well established. Smoking, a high dietary fat intake, and lack of exercise have all been identified as independent risk factors for the development of atherosclerosis. ${ }^{1}$ To reduce a person's cardiovascular risk it is important first to identify the modifiable risk factors. Where appropriate, attempts may then be made to encourage change. Prochaska and DiClemente have suggested that the ability to initiate and sustain this change depends on several factors. ${ }^{2}$ Firstly, people must be aware of the harm caused to their health by their behaviour. Secondly, there must be a desire to change this behaviour. Thirdly, this desire must be translated into action.

Cardiovascular disease has a multifactorial aetiology, and many risk factors act synergistically. ${ }^{3}$ As a result, even minor modifications in one lifestyle factor in the presence of other risk factors can have large effects on overall risk. It is unclear whether this compounding it influences their motivation to modify behaviour.

We examined the relation between subjects' estimated level of risk and their beliefs about and desire to risk effect is understood by those affected and whether

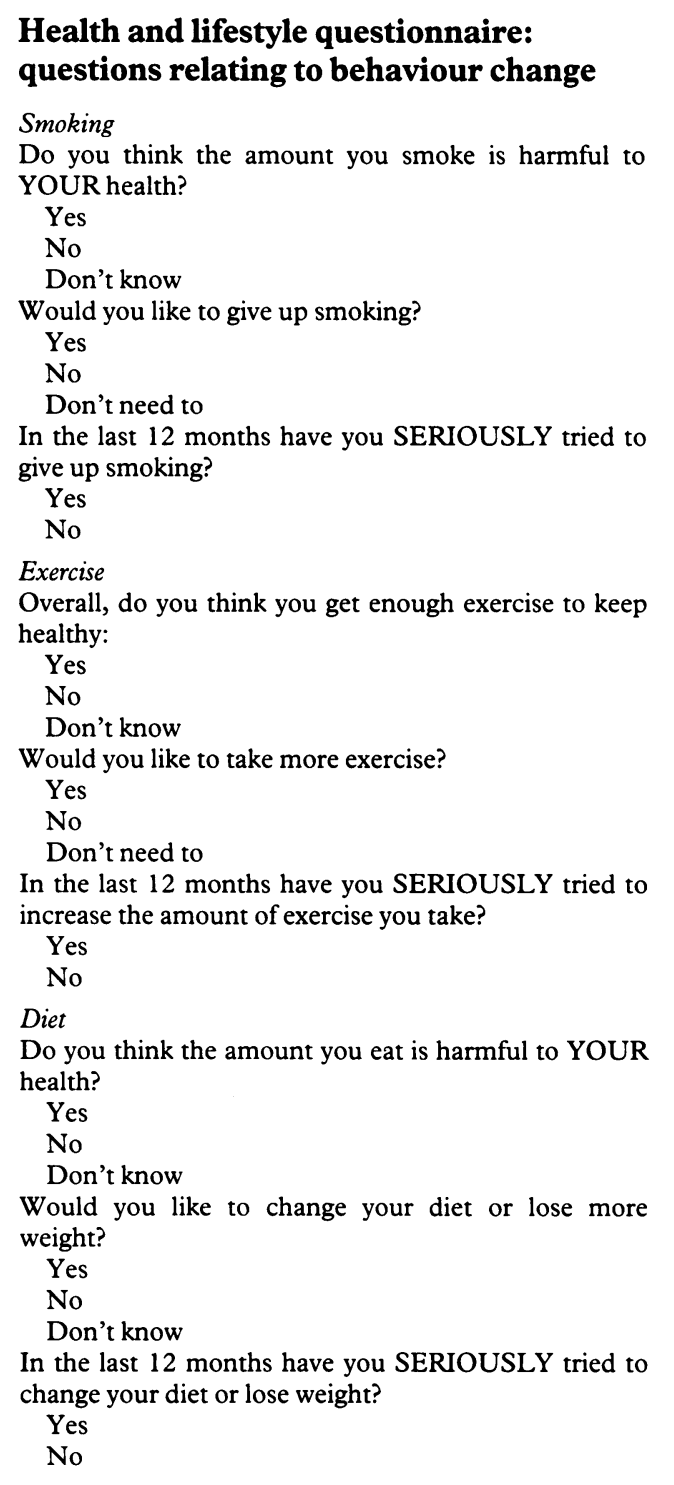

modify smoking, current diet, and level of exercise. A secondary objective was to see whether any sociodemographic variables were associated with the beliefs or motivation of those people at greatest risk of developing cardiovascular disease.

\section{Subjects and methods}

This study was performed as part of OXCHECK, which is a large randomised controlled trial examining the effectiveness of nurse administered health checks in modifying risk factors for cardiovascular disease. The methods have been reported in detail and are summarised here. ${ }^{4}$

A health and lifestyle questionnaire was mailed to 17965 people aged 35-64 registered with five general practices in Bedfordshire during 1989. The main part of the questionnaire had been used in a previous study based in the Oxford region. ${ }^{5}$ Subjects were asked 
whether they perceived a risk to their own health as a result of specific lifestyle behaviours (smoking, alcohol exercise level, and diet); whether they wanted to modify their current lifestyle; and whether they had made a serious attempt to do so during the previous year (box). In view of the controversies surrounding the relation between alcohol consumption and cardiovascular risk ${ }^{b}$ we have not analysed this behaviour. The estimated response rate for completion of the questionnaire after adjusting for people who had died or moved out of the area was $80 \cdot 3 \%{ }^{4}$ Respondents $(n=11090)$ were randomised to be offered a health check during one of four years beginning in June 1989. Data for the present study are based on 5803 people who had completed the lifestyle questionnaire and attended for a health check before March 1992.

Eight possible cardiovascular risk factors were identified at the time of the health check: current smoker; history of high blood pressure requiring drug treatment; history of diabetes mellitus requiring treatment; physical inactivity; high fat intake; overweight (body mass index $>35 \mathrm{~kg} / \mathrm{m}^{2}$ ) or obese (body mass index $>30 \mathrm{~kg} / \mathrm{m}^{2}$ ); history of ischaemic heart disease, angina, stroke, or transient ischaemic episode; and family history of ischaemic heart disease, angina, stroke, or transient ischaemic episodes in a first degree relative before 60 years of age.

TABLE I-Prevalence of cardiovascular risk factors in study population

\begin{tabular}{|c|c|c|c|c|c|}
\hline \multirow{2}{*}{$\frac{\text { Risk factor }}{\text { Current smoking }}$} & $\begin{array}{l}\text { No of subjects } \\
\quad(n=5803)\end{array}$ & \multicolumn{2}{|c|}{ Prevalence $(\%)$} & \multicolumn{2}{|c|}{$95 \%$ Confidence interval } \\
\hline & 1604 & & $27 \cdot 6$ & & $26 \cdot 5$ to $28 \cdot 8$ \\
\hline Men & 812 & 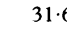 & & 29.8 to 33.4 & \\
\hline Women & 792 & $24 \cdot 5$ & & 23.0 to 25.9 & \\
\hline History of high blood pressure on treatment & 709 & & $12 \cdot 2$ & & 11.4 to 13.1 \\
\hline Men & 287 & 11.2 & & $10 \cdot 0$ to $12 \cdot 4$ & \\
\hline Women & 422 & 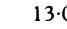 & & 11.9 to 14.2 & \\
\hline History of diabetes & 112 & & 1.9 & & 1.6 to 2.3 \\
\hline Men & 57 & $2 \cdot 2$ & & 1.7 to 2.9 & \\
\hline Women & 55 & 1.7 & & $1 \cdot 3$ to $2 \cdot 2$ & \\
\hline Physical inactivity & 548 & & $9 \cdot 4$ & & $8 \cdot 7$ to $10 \cdot 2$ \\
\hline Men & 268 & $10 \cdot 4$ & & $9 \cdot 3$ to 11.6 & \\
\hline Women & 280 & 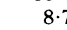 & & $7 \cdot 7$ to $9 \cdot 9$ & \\
\hline High dietary fat intake ${ }^{\star}$ & 1534 & & $26 \cdot 4$ & & $25 \cdot 3$ to $27 \cdot 6$ \\
\hline Men & 926 & $36 \cdot 1$ & & $34 \cdot 2$ to $37 \cdot 9$ & \\
\hline Women & 608 & 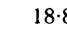 & & $17 \cdot 4$ to $20 \cdot 1$ & \\
\hline Overweight $\dagger$ & 3040 & & $52 \cdot 4$ & & $51 \cdot 1$ to $53 \cdot 7$ \\
\hline Men & 1459 & 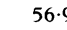 & & 54.9 to 58.8 & \\
\hline Women & 1581 & 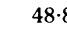 & & $47 \cdot 1$ to $50 \cdot 6$ & \\
\hline History of cardiovascular disease $\ddagger$ & 224 & & 3.9 & & $3 \cdot 4$ to $4 \cdot 4$ \\
\hline Men & 145 & $5 \cdot 7$ & & 4.8 to 6.6 & \\
\hline Women & 79 & $2 \cdot 4$ & & 1.9 to 3.0 & \\
\hline Family history of cardiovascular disease $\$$ & 982 & & $16 \cdot 9$ & & 16.0 to 17.9 \\
\hline Men & 422 & 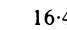 & & $15 \cdot 0$ to $17 \cdot 9$ & \\
\hline Women & 560 & 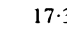 & & 16.0 to 18.6 & \\
\hline
\end{tabular}

${ }^{\star}$ Estimated total fat intake $<110 \mathrm{~g} /$ day.

†Body mass index $25 \mathrm{~kg} / \mathrm{m}^{2}$.

†Body mass index $25 \mathrm{~kg} / \mathrm{m}^{2}$.

†Heart attack, angina, stroke or transient ischaemic episode.
§Heart attack, angina, stroke or transient episode in a first degree relative before the age of 60 years.

TABLE II-Perceptions of lifestyle behaviour according to levels of risk of cardiovascular disease

\begin{tabular}{|c|c|c|c|}
\hline $\begin{array}{l}\text { Risk factor } \\
\text { (lifestyle behaviour) }\end{array}$ & $\begin{array}{l}\text { No }(\%) \\
\text { perceive } \\
\text { harmful }\end{array}$ & $\begin{array}{l}\text { No }(\%) \\
\text { want to } \\
\text { change }\end{array}$ & $\begin{array}{l}\text { No }(\%) \\
\text { tried to } \\
\text { change }\end{array}$ \\
\hline \multicolumn{4}{|l|}{ Smoking (smoking): } \\
\hline Light smoker $(n=997)$ & $570(70 \cdot 3)$ & $715(76 \cdot 3)$ & $347(35 \cdot 3)$ \\
\hline Heavy smoker $(n=607)$ & $450(85 \cdot 6)$ & $497(84 \cdot 1)$ & $183(30 \cdot 3)$ \\
\hline$\chi^{2}, p$ value & $4 \cdot 2,<0.001$ & $13 \cdot 4,<0.001$ & $4 \cdot 2,<0.05$ \\
\hline \multicolumn{4}{|l|}{ Physical inactivity (exercise) ${ }^{\star}$ : } \\
\hline Active $(n=1632)$ & $585(38 \cdot 7)$ & $945(70 \cdot 3)$ & $506(31 \cdot 3)$ \\
\hline Moderately active $(n=3623)$ & $1396(44 \cdot 4)$ & $1905(62 \cdot 2)$ & $751(21)$ \\
\hline Inactive $(n=548)$ & $350(73 \cdot 7)$ & $375(74 \cdot 4)$ & $102(18 \cdot 8)$ \\
\hline$x^{2}, p$ value & $127 \cdot 1,<0.001$ & $0 \cdot 8, \mathrm{NS}$ & $63.0,<0.001$ \\
\hline \multicolumn{4}{|l|}{ High dietary fat intake (diet): } \\
\hline Low $(n=2324)$ & $391(19 \cdot 1)$ & $1284(57 \cdot 8)$ & $1146(49 \cdot 6)$ \\
\hline Medium $(n=1945)$ & $265(15 \cdot 7)$ & $938(50 \cdot 7)$ & $666(34 \cdot 3)$ \\
\hline High $(n=1534)$ & $188(14 \cdot 1)$ & $579(40 \cdot 4)$ & $367(24 \cdot 0)$ \\
\hline$\chi^{2}, p$ value & $15 \cdot 3,<0.001$ & $104.3, p<0.001$ & $260.9,<0.001$ \\
\hline \multirow{2}{*}{\multicolumn{4}{|c|}{$\begin{array}{l}\text { Overweight (diet): } \\
\text { Body mass index }\left(\mathrm{kg} / \mathrm{m}^{2}\right)\end{array}$}} \\
\hline & & & \\
\hline$\leqslant 24(n=2758)$ & $160(6 \cdot 4)$ & $752(28 \cdot 5)$ & $630(22.9)$ \\
\hline $25-29(n=2263)$ & $394(20 \cdot 6)$ & $1400(65 \cdot 6)$ & $1043(46 \cdot 2)$ \\
\hline$\geqslant 30(n=777)$ & $289(44 \cdot 5)$ & $647(87 \cdot 7)$ & $504(655)$ \\
\hline$\chi^{2}, \mathrm{p}$ value & $558.3, p<0.001$ & $1087 \cdot 2, \mathrm{p}<0.001$ & $576.8,<0.001$ \\
\hline
\end{tabular}

${ }^{\star}$ Respondents who thought they did not get enough exercise to keep healthy.

Percentages are based on respondents perceiving a lifestyle behaviour to be harmful or wanting to change it, and excluding those who answered "Don't know.".
Height, weight, and blood pressure were measured by a trained nurse during the health check using standard protocols. ${ }^{4}$ Detailed classification and grading of lifestyle factors has been described. ${ }^{7}$ Respondents were classified as either current smokers or non-smokers. Smokers were further subdivided into light smokers (less than 15 cigartettes a day) or heavy smokers (15 or more cigarettes a day).

Exercise gradings (inactive, moderately active, and active) were based on the assessment of leisure time and work activity levels reported at the health check. Subjects were defined as inactive if they undertook no physical activity during work hours; undertook vigorous leisure activity (such as football, jogging, cycling, or swimming) less than once a month; and undertook less vigorous exercise (such as walking, gardening, or golf) twice a week or less. Those who undertook vigorous activity during work hours or at least once a week during their leisure time were regarded as being active. All other persons were classified as moderately active.

Dietary fat intake was classified as high, medium, or low based on a score derived from the reported frequency of intake of 11 food groups. Subjects with a high dietary fat score had an estimated intake greater than $110 \mathrm{~g} /$ day. This would be equivalent to a fat intake of $45 \%$ of energy on a $9.2 \mathrm{MJ}(2200 \mathrm{kcal})$ diet, which is well above the dietary reference value of $35 \% .{ }^{\circ}$ Data were also collected on social and demographic characteristics including age, sex, marital status, and social class. ${ }^{9}$

\section{STATISTICAL ANALYSIS}

Data were analysed with SAS-PC statistical software. We used $\chi^{2}$ tests for trend ${ }^{11}$ to establish whether increasing risk levels are associated with a change in perception of risk, or a desire to modify behaviour. A separate analysis was also performed to determine whether any social or demographic variables affected the perception of risk or desire to modify behaviour of those at increased risk. All $\mathrm{p}$ values quoted are two tailed; $95 \%$ confidence intervals were calculated using the confidence interval analysis program. ${ }^{\prime \prime}$

Crude odds ratios were calculated for the likelihood of an individual perceiving his or her diet to be harmful and having tried to change the current diet according to the presence or absence of each of the eight cardiovascular risk factors. To estimate the independent effect of each risk factor on health beliefs about diet, adjusted odds ratios were calculated by logistic regression analysis. All risk factors were treated as dichotomous.

\section{Results}

Table I shows the prevalences of the eight cardiovascular risk factors included in the study. Eighteen per cent (1027) of the study sample had no cardiovascular risk factors, while $35 \%$ (2053) had one risk factor, $30 \%$ (1748) had two risk factors, and $17 \%$ (975) had three or more risk factors. These rates and personal characteristics were similar to those reported in an earlier publication from the first 12 months of the OXCHECK trial. ${ }^{4}$

\section{PERCEPTIONS OF RISK TO HEALTH}

Table II shows the perceptions of risk associated with each lifestyle factor. Only $188(14 \%$; $95 \%$ confidence interval $12 \%$ to $16 \%$ ) of people with a high dietary fat intake perceived their diet to be a health risk, in contrast to $1020(76 \% ; 74 \%$ to $79 \%)$ of smokers and $350(74 \% ; 70 \%$ to $78 \%)$ of inactive people who felt that their behaviour was harmful. Among obese people, 289 ( $45 \%$; $40 \%$ to $48 \%$ ) perceived their current diet to 
TABLE III-Perceptions of lifestyle behaviour according to overall cardiovascular risk. Values are numbers (percentages) of subjects

No of risk factors

\begin{tabular}{|c|c|c|c|c|c|c|}
\hline & $\begin{array}{c}0 \\
(\mathrm{n}=1027)\end{array}$ & $\begin{array}{c}1 \\
(n=2053)\end{array}$ & $\begin{array}{c}2 \\
(n=1748)\end{array}$ & $\begin{array}{c}\geqslant 3 \\
(\mathrm{n}=975)\end{array}$ & $\begin{array}{l}\chi^{2} \text { for } \\
\text { trend }\end{array}$ & $\mathrm{p}$ Value \\
\hline \multicolumn{7}{|l|}{ Smoking ${ }^{\star}:$} \\
\hline Perceive harmful & & $200(69 \cdot 0)$ & $463(80 \cdot 5)$ & $357(75 \cdot 3)$ & $2 \cdot 1$ & NS \\
\hline Want to quit & & $245(73 \cdot 6)$ & $533(81 \cdot 6)$ & $434(80 \cdot 1)$ & 3.9 & NS \\
\hline Tried to quit & & $102(29.5)$ & $235(34.5)$ & $193(34.5)$ & $2 \cdot 0$ & NS \\
\hline \multicolumn{7}{|l|}{ Exercise } \\
\hline Perceive harmfult & $342(37 \cdot 2)$ & $831(45 \cdot 4)$ & $729(47 \cdot 2)$ & $429(51 \cdot 4)$ & $34 \cdot 6$ & $<0.001$ \\
\hline Want to increase & $584(69 \cdot 4)$ & $1144(66 \cdot 1)$ & $971(64 \cdot 8)$ & $526(62 \cdot 5)$ & $9 \cdot 0$ & $<0.01$ \\
\hline Tried to increase & $275(27 \cdot 1)$ & $521(25 \cdot 7)$ & $343(19 \cdot 9)$ & $220(22 \cdot 8)$ & $14 \cdot 2$ & $<0.001$ \\
\hline \multicolumn{7}{|l|}{ Diet: } \\
\hline Perceive harmful & $77(8 \cdot 2)$ & $286(16 \cdot 1)$ & $280(181 \cdot 7)$ & $201(24 \cdot 1)$ & $82 \cdot 3$ & $<0.001$ \\
\hline Want to change & $325(32 \cdot 9)$ & $981(50 \cdot 2)$ & $936(56 \cdot 6)$ & $559(61 \cdot 2)$ & $164 \cdot 5$ & $<0.001$ \\
\hline Tried to change & $284(27 \cdot 7)$ & $804(39 \cdot 3)$ & $696(40 \cdot 1)$ & $395(40 \cdot 6)$ & 31.6 & $<0.001$ \\
\hline
\end{tabular}

^Responses limited to smokers only $(n=1604)$

Those respondents who thought they did not get enough exercise to keep healthy.

Percentages are based on respondents perceiving a lifestyle behaviour to be harmful or wanting to change it, and excluding those who answered "Don't know."

TABLE IV-Effect of cardiovascular risk factors on health beliefs about diet

\begin{tabular}{|c|c|c|c|c|c|c|}
\hline \multirow[b]{2}{*}{ Risk factor } & \multicolumn{2}{|c|}{$\begin{array}{c}\text { Current diet } \\
\text { perceived as harmful }\end{array}$} & \multirow[b]{2}{*}{$\begin{array}{l}\mathrm{p} \text { Value for } \\
\text { adjusted } \\
\text { odds ratio* }\end{array}$} & \multicolumn{2}{|c|}{ Tried to change diet $\dagger$} & \multirow[b]{2}{*}{$\begin{array}{l}\mathrm{p} \text { Value for } \\
\text { adjusted } \\
\text { odds ratio }\end{array}$} \\
\hline & $\begin{array}{l}\text { Crude } \\
\text { odds ratio }\end{array}$ & $\begin{array}{l}\text { Adjusted odds ratio } \\
\text { (95\% confidence } \\
\text { interval) }\end{array}$ & & $\begin{array}{l}\text { Crude } \\
\text { odds ratio }\end{array}$ & $\begin{array}{l}\text { Adjusted odds ratio } \\
\text { (95\% confidence } \\
\text { interval) }\end{array}$ & \\
\hline Smoking & 0.60 & $0.65(0.54$ to 0.79$)$ & $<0.001$ & 0.67 & $0.73(0.64$ to 0.84$)$ & $<0.001$ \\
\hline High blood pressure & 1.71 & $1.35(1.08$ to 1.68$)$ & NS & $1 \cdot 40$ & $1.04(0.87$ to 1.24$)$ & NS \\
\hline Diabetes & $1 \cdot 19$ & $0.84(0.48$ to 1.45$)$ & NS & $2 \cdot 01$ & $1.51(1.00$ to 2.29$)$ & 0.05 \\
\hline Inactive & 1.30 & $1.30(1.01$ to 1.68$)$ & 0.04 & 1.03 & $1.01(0.83$ to 1.23$)$ & NS \\
\hline High fat intake & 0.77 & $0.82(0.68$ to 0.98$)$ & 0.03 & 0.42 & $0.42(0.37$ to 0.48$)$ & $<0.01$ \\
\hline Obesity & $5 \cdot 31$ & $5 \cdot 14(4 \cdot 26$ to $6 \cdot 21)$ & $<0.001$ & $3 \cdot 52$ & $3.51(3.12$ to 3.93$)$ & $<0.01$ \\
\hline Cardiovascular disease & $1 \cdot 11$ & $0.76(0.50$ to 1.13$)$ & NS & $1 \cdot 39$ & $1.06(0.79$ to 1.44$)$ & NS \\
\hline $\begin{array}{l}\text { Family history of } \\
\text { cardiovascular disease }\end{array}$ & 1.27 & $1.24(1.01$ to 1.51$)$ & 0.04 & $1 \cdot 20$ & $1.18(1.02$ to 1.38$)$ & 0.03 \\
\hline
\end{tabular}

*Adjusted for all other risk factors.

†At least one serious attempt to modify diet during the past 12 months.

be harmful. The proportion of people who perceived an associated risk to their health increased with the level of smoking and inactivity. However, for dietary fat intake, those with the highest intake were least likely to perceive their diet as harmful. All of these trends were significant $(p<0 \cdot 001)$.

The proportion of people who perceived a health risk associated with diet and lack of exercise increased with the number of cardiovascular risk factors present (table III). Most smokers perceived their habit to be harmful irrespective of the number of additional risk factors present (table III).

The perceptions of risk in relation to diet were complex. Even among people with three or more cardiovascular risk factors less than $25 \%$ ( $21 \%$ to $27 \%$ ) of subjects believed their diet was harmful. Two hundred and one $(42 \% ; 36 \%$ to $48 \%)$ of obese people with three or more risk factors perceived their diet to be harmful but only $107(14 \% ; 11 \%$ to $17 \%)$ with a high fat intake perceived their diet to be harmful.

We used logistic regression to explore further the effect that being overweight and having a high fat intake have on the perception of health risks associated with diet (table IV). Being obese emerged as the most powerful determinant of perceived dietary risk. The contribution of other risk factors was substantially less. Both smoking and a high fat intake had small, but significant inverse effects on the perceived harmfulness of the diet.

Significantly more female than male smokers perceived their habit to be harmful $(532(79 \% ; 76 \%$ to $82 \%)$ v $488(74 \% ; 70 \%$ to $77 \%), \mathrm{p}<0.05)$. Obese women were also significantly more likely to perceive their diet to be harmful than obese men $(199(49 \%$; $44 \%$ to $54 \%$ ) $v 90(37 \% ; 31 \%$ to $43 \%), \mathrm{p}<0.01)$. Among people with a high fat diet women were no more likely than men to perceive their diet as harmful.

Smokers in lower social classes were significantly less likely to perceive their smoking as harmful compared with those in higher social classes $\left(\chi^{2}\right.$ for trend $4 \cdot 1, p<0 \cdot 05)$. There was no effect of social class on the perceptions of risk those who were inactive, obese, or who consumed a high fat diet. No significant association was found between marital status and perception of risk for any of the lifestyle factors.

DESIRE TO CHANGE AND ATTEMPT TO CHANGE

Of the 1020 smokers who perceived smoking to be a health risk, $931(91 \% ; 89 \%$ to $93 \%)$ wanted to reduce their smoking but only $400(39 \% ; 36 \%$ to $42 \%$ ) claimed to have seriously tried to do so during the past year. The corresponding figures were $171(91 \% ; 86 \%$ to $95 \%)$ and $114(61 \% ; 54 \%$ to $68 \%)$ for the 188 people with a high fat diet who perceived their diet as harmful and $282(98 \% ; 95 \%$ to $99 \%)$ and $221(76 \% ; 72 \%$ to $81 \%)$ for 289 obese people who perceived their diet as harmful.

Being overweight seemed to be the main motivator for dietary change, as well as the main factor associated with an actual attempt to change diet (table IV). Both smoking and a high fat intake were significantly associated with a lower motivation to change diet, and a lower likelihood of having tried to change.

The proportion of people both desiring and seriously trying to change their diet rose with increasing number of risk factors (table III). In contrast, the motivation to increase exercise, and attempts to do so, were inversely related to the number of risk factors present. No trend was seen with respect to stopping smoking.

The effect of sex on the motivation to change lifestyle was similar to that seen with perception of risk. Significantly more female smokers reported that they had tried to quit than male smokers $(293(37 \%$; $34 \%$ to $40 \%)$ v $237(30 \% ; 27 \%$ to $33 \%), \mathrm{p}=0.001)$. Women who were obese or who had a high dietary fat intake were significantly more motivated to try to change their diet than men (363 (76\%; $72 \%$ to $80 \%$ ) $v 141(48 \% ; 43 \%$ to $54 \%), \mathrm{p}<0.001$ for the obese and $199(33 \% ; 29 \%$ to $37 \%)$ v $168(18 \% ; 16 \%$ to $21 \%$ ), $\mathrm{p}<0.001$ for those with a high dietary fat intake).

Social class and marital status had no significant effect on the motivation to change diet or exercise. However, more smokers in high social classes reported having tried to quit $\left(\chi^{2}\right.$ for trend $\left.4 \cdot 8, p<0.05\right)$. There was also a trend for younger people (aged 35-44 years) consuming a high fat diet to be more likely to have reported trying to change their current diet during the past year than people aged $45-54$ years and 55-64 years consuming a high fat diet $\left(\chi^{2}\right.$ for trend $\left.7 \cdot 2, p<0 \cdot 01\right)$. There was no association between the age of subjects and reported attempts to change lifetyle behaviours in other high risk groups.

\section{Discussion}

Our results indicate that the health risks of smoking and lack of exercise are recognised by most people. Attitudes towards diet seem to be more complex. Being overweight is the main predictor of an individual's perception of diet as harmful to health; the contribution of other risk factors is small. Large differences existed between the sexes, with obese women more likely to believe that their diet is harmful than obese men. Similar findings have been reported previously and suggest that social attitudes about sex and body image stereotyping may contribute to these differences. ${ }^{12}$

Cardiovascular risk is associated more with the proportion of saturated fat in the diet than with the degree of obesity. ${ }^{13}$ Hence, the negative relation seen in this study between fat intake and both the perception of diet as harmful and the desire to modify the diet is important. Several possible explanations may account 
for these findings. People with high fat intake may be less aware of the fat content of their diet and of the associated risks to their health than people who are better informed about diet in general. Conversely, those consuming a low fat diet may represent a particularly health conscious group, in which the perception of what constitutes a desirable fat intake is even lower than currently accepted recommendations ${ }^{8}$ and motivation to make further dietary change is high. A further possibility is that those who perceived an increased risk associated with a high fat diet at the time of the questionnaire had changed to a low fat diet before attending for their health check (when the dietary assessment was performed). This explanation would be consistent with the high proportion of people with a low fat intake who reported having seriously tried to change their diet in the previous year.

EDUCATING THE PUBLIC

These results have important implications for setting priorities in prevention of cardiovascular disease in primary care and public health, particularly as the new general practitioner contract requires general practitioners to provide health promotion to their patients. ${ }^{14}$ The reported rate of advice on these four lifestyle factors received from general practitioners is relatively low. ${ }^{7}$ Our results reinforce the need for greater efforts to educate the public, particularly about the health risks associated with a high fat intake. Routinely including a simple assessment of diet in the evaluation of a patient's cardiovascular risk in primary care could help achieve this goal. However, it it important to recognise that the relation between a patient's knowledge, attitudes, and behaviour is complex and needs to be taken into account when planning any strategy for preventing disease. ${ }^{15}$

The potentially greater benefits of changing lifestyle when multiple risk factors are present need to be more widely disseminated. Our results indicate that the effects of compounding risk are poorly understood by the general public.

A further challenge for primary care is to motivate people to change their behaviour. In the present study, most smokers were not only aware of the risk posed to their health but also expressed a desire to stop smoking. These findings are almost identical to those in a similar survey carried out in the Oxford region during the mid-1980s. ${ }^{5}$ However, only $34 \%$ of smokers reported having tried to stop smoking during the past 12 months; this figure is consistent with previous reports. ${ }^{16}$

Effective support strategies for primary care are urgently required to help those who wish to modify their diet, smoking habit, or exercise pattern. The OXCHECK trial is currently evaluating a method of providing such advice through practice nurses and systematic health checks.

We thank the Imperial Cancer Research Fund OXCHECK Study Group for access to the data; Drs D Mant and G Fowler for technical advice; $P$ Yudkin for statistical advice. CS is the Sir Robert Menzies memorial scholar in medicine for Australia, funded by the Menzies Trust.

1 Manson JE, Tosteson H, Ridker PM, Satterfield S, Herbert P, O'Connor GT, et al. The primary prevention of myocardial infarction. $N$ Engl $\mathcal{J} \mathrm{Med}$ 1992;326:1406-16.

2 Prochaska JO, DiClemente CO. Towards a comprehensive model of change. In: Miller WR, Heather N, eds. Treating addictive behaviours: process of change. New York: Plenum, 1986:3-27.

3 Anderson KM, Odell PM, Wilson PWF, Kannel WB. Cardiovascular disease risk profiles. Am Heart f 1990;121:293-8.

4 Imperial Cancer Research Fund OXCHECK Study Group. Prevalence of risk factors for heart disease in OXCHECK trial: implications for screening in primary care. $B M 7$ 1991;302:1057-60.

5 Coulter $\mathrm{A}$. Lifestyles and social class: implications for primary care. $\exists R \mathrm{Coll}$ Gen Pract 1987;37:533-6.

6 Kannel WB. New perspectives on cardiovascular risk factors. Am Heart $\mathfrak{J}$ 1987;114:213-9.

7 Silagy C, Muir J, Coulter A, Thorogood M, Yudkin P, Loe R. Lifestyle advice in general practice: rates recalled by patients. $B M F$ 1992;305:871-4.

8 Committee on Medical Aspects of Food Policy. Dietary reference values for food energy and nutrients for the United Kingdom. London: HMSO, 1991. (Repor on Health and Social Subjects 41.)

9 Office of Population Censuses and Surveys. Classification of occupations. London: HMSO, 1980

10 Armitage P, Berry G. Statistical methods in medical research. 2nd ed. Oxford: Blackwell. 1987:372-4.

1 Gardner MJ, Gardner SB, Winter PD. Confidence interval analysis version 1.1. London: BMJ, 1991.

12 Thorogood M, Coulter A. Food for thought, women and nutrition. In: Roberts $\mathrm{H}$, ed. Women's health matters. London: Routledge, 1992

13 Keys A, Menotti A, Karnoven MJ, Aravanis C, Blackburn H, Buzina R, et al. The diet and 15 year death rate in the seven countries study. Am $\mathcal{J}$ Epidemiol 1986;124:903-15

14 General Medical Services Committee. The new health promotion package. London: British Medical Association, 1993.

15 Tuckett D, Boulton M, Olson C, Williams A. Meetings between experts. An approach to sharing ideas in medical consultations. London: Tavistock Publications, 1985:173-7.

16 Jamrozik K, Vessey MP, Fowler GH, Wald N, Parker G, Van Vunakis H. Controlled trial of three different antismoking interventions in general practice. BMf 1984;288:1499-503.

(Accepted 19 April 1993)

\section{Correction}

Developing a register of randomised controlled trials in primary care

An editorial error occurred in this paper by Silagy (3 April, pp $897-900)$. In table III the number of articles identified manually from the Scandinavian fournal of Health Care should be 24 not 20 and the difference between the number retrieved manually and by Medline should be 7 not 3 .

\section{ONE HUNDRED YEARS AGO}

\section{THE CLOTHING OF THE POLICE}

The worst of the hot weather having now passed away, we fear that the question of the clothing of the police force, which could not fail to attract the attention of everyone last week, will now fade into the limbo of things forgotten until again we find ourselves confronted with another blast of fervent heat, and another crowd of fainting constables. Nevertheless we might, in justice to a great number of most deserving public servants, consider well how far the present uniform is the best that could be devised for the purpose of clothing men who have, from the nature of their duties, to be exposed to the greatest possible variations of weather and the extremest alternations of temperature. No one can pretend that if one had to commence de novo to evolve a costume suitable for our guardians of the peace the present curious design could by any possibility have been hit upon. For a force which may any day, between leaving home and coming in again, have to be exposed to morning chills, to midday heats, and to cold drizzles in the afternoon, the uniform should not merely be warm and watertight, but capable of variation and ventilation. As it is, everything is sacrificed to correctness of appearance. No tightly-fitting tunic ever can be really satisfactory for the purpose. Nothing looks worse, either on soldier or policeman, than an unbuckled belt or an unbuttoned tunic, and the first step should be to get rid of these two articles, which between them make it impossible to obtain comfort without breach of discipline. Something of the nature of a Norfolk jacket is what is wanted-something which, by drawing the folds together and tightening up, can be made thicker and warmer in wintry chills, and yet can be loosened and freely ventilated in summer heats without appearing utterly disorderly.

(BMF 1893;ii:482.) 